\title{
Acyclic Sesquiterpenes from the Fruit Pericarp of Sapindus saponaria Induce Ultrastructural Alterations and Cell Death in Leishmania amazonensis
}

\author{
Amanda Louzano Moreira, ${ }^{1}$ Débora Botura Scariot, ${ }^{1}$ \\ Bruna Luíza Pelegrini, ${ }^{1}$ Greisiele Lorena Pessini, ${ }^{2}$ Tânia Ueda-Nakamura, ${ }^{1}$ \\ Celso Vataru Nakamura, ${ }^{1}$ and Izabel Cristina Piloto Ferreira ${ }^{1}$ \\ ${ }^{1}$ Programa de Pós-Graduação em Ciências Farmacêuticas, Universidade Estadual de Maringá, \\ Avenida Colombo 5790, Jd. Universitário, Maringá, PR, Brazil \\ ${ }^{2}$ Laboratório de Inovação Tecnológica no Desenvolvimento de Fármacos e Cosméticos, Universidade Estadual de Maringá, \\ Avenida Colombo 5790, Jd. Universitário, Maringá, PR, Brazil
}

Correspondence should be addressed to Izabel Cristina Piloto Ferreira; icpferreira@uem.br

Received 5 March 2017; Revised 29 June 2017; Accepted 19 July 2017; Published 22 August 2017

Academic Editor: Juntra Karbwang

Copyright (C) 2017 Amanda Louzano Moreira et al. This is an open access article distributed under the Creative Commons Attribution License, which permits unrestricted use, distribution, and reproduction in any medium, provided the original work is properly cited.

\begin{abstract}
Previous studies reported antiprotozoal activities of Sapindus saponaria L. The aim of this work was the evaluation of antileishmanial activity and mechanism of action of extract and fractions of S. saponaria L. Hydroethanolic extract (EHA) obtained from fruit pericarps was fractionated using solid-phase extraction in a reversed phase, resulting in fractions enriched with saponins (SAP fraction) and acyclic sesquiterpene oligoglycosides (OGSA fraction). The activities of EHA, SAP, and OGSA were evaluated by antiproliferative assays with promastigote and intracellular amastigote forms. Cytotoxicity on macrophages and hemolytic activity were also analyzed. Morphological and ultrastructural changes in Leishmania amazonensis promastigotes were evaluated by electron microscopy. Flow cytometry was used to investigate mitochondrial dysfunction and phosphatidylserine exposure. OGSA was more selective for parasites than mammalian J774A1 macrophage cells, with selectivity indices of 3.79 and 7.35 , respectively. Our results showed that only the OGSA fraction did not present hemolytic activity at its $\mathrm{IC}_{50}$ for promastigote growth. Electron microscopy revealed changes in parasite flagellum, cell body shape, and organelle size, mainly mitochondria. Flow cytometry analysis indicated mitochondrial membrane and cell membrane dysfunction. OGSA showed antileishmanial activity, resulting in several changes to protozoa cells, including mitochondrial depolarization and early phosphatidylserine exposure, suggesting a possible apoptotic induction.
\end{abstract}

\section{Introduction}

Sapindus saponaria L. (Sapindaceae) is a tropical tree species that is regularly found within the north, northeast, and central west areas of Brazil. Its height ranges from 4 to $9 \mathrm{~m}$, and it presents bright brown-colored fruits $2 \mathrm{~cm}$ in diameter [1].

S. saponaria L., easily accessible owing to its popularity, has diverse traditional uses in the treatment of diseases of the nervous, respiratory, and genitourinary systems, in addition to being used to heal skin illnesses and as a biocide.
The fruits, bark, and root of this species are employed in folk medicine as an astringent, soothing, expectorant, diuretic, tonic, and antitussive agent [2]. Potential activities of Sapindus species, including antimicrobial, antidiabetic, molluscicidal, cytotoxic, fungicidal, and anti-inflammatory, are attributed to the presence of, among other substances, glycosides [3].

Fruits of S. saponaria L. possess various glycosides in their pericarps. There are 30 saponins derived from the hederagenin triterpene oleanolic acid and 63 acyclic sesquiterpene oligoglycosides, as shown by liquid chromatography with 
UV-detection and MS (LC/UV/ESI-MS) and MS/MS fragmentation studies [4].

Glycosides are also considered promising antiprotozoal agents, particularly against Leishmania spp. [5-9]. The protozoa that cause leishmaniasis are transmitted by sandflies (insects of Lutzomyia spp. and Phlebotomus spp.) that are intermediate hosts of flagellated promastigote forms of the parasite $[10,11]$.

An understudied disease, leishmaniasis, is prevalent in America, Africa, and Asia, mainly in developing countries, but also in Europe [12]. Despite its prevalence, few drugs have been applied to treat this illness, and high toxicity and pronounced side effects have been reported. Pentavalent antimonials, used as the first-line treatment for cutaneous leishmaniasis, are effective, but usually other limitations are observed, such the necessity for long-term treatment and the resulting difficulty in patient adherence [13-15].

Currently, elucidating the chemical composition of plant extracts, which are easily accessed by low-income populations, has become relevant to treating neglected diseases and discovering substances with new therapeutic mechanisms. Therefore, this study aimed to examine the antileishmanial activity and mechanism of action of extracts and fractions of S. saponaria L. on L. amazonensis parasites.

\section{Materials and Methods}

2.1. Obtaining the Hydroethanolic Extract, Acyclic Sesquiterpene Oligoglycosides, and Saponins of S. saponaria L. Fruits of $S$. saponaria $\mathrm{L}$. were collected during maturation on campus at the State University of Maringá on September 14, 2012, and the vegetal material was identified by the Department of Botany, where the sample of this species was deposited as number HUM 11710. The fruits were washed and separated into pericarps and seed. Pericarps were subjected to maceration with occasional stirring until exhaustion, using an extraction solvent mixture of ethanol: water 9:1 (v/v). This solution was filtered, and the solvent evaporated under reduced pressure in a rotary evaporator at $40^{\circ} \mathrm{C}$. The portion not volatilized in this process was lyophilized to become the hydroethanolic extract (EHA). To obtain two separate classes of glycosides, acyclic sesquiterpene oligoglycosides (called fraction OGSA) and saponins (called SAP fraction), $1000 \mathrm{mg}$ of EHA was subjected to a solid-phase extraction in a cartridge with a reverse phase of octadecylsilane (ODS, Supelco Supelclean LC-18, $6 \mathrm{~mL}, 1000 \mathrm{~g}$ ) under reduced pressure on a Supelco system. The eluents used were $5 \mathrm{~mL}$ aliquots of the mixtures of ACN (chromatographic grade) : $\mathrm{H}_{2} \mathrm{O}$ (purified with a Milli-Q system) in proportions (v/v) of $2: 8,3: 7,4: 6$, $5: 5,6: 4,7: 3$, and $10: 0$, in that order.

2.2. Glycoside Characterization by Mass Spectrometry with Electrospray Ionization (ESI-MS). Analyses were performed on a mass spectrometer model MICRO MASS QUATTRO LC, equipped with triple quadrupole and electrospray ionization in negative mode. The samples were diluted in methanol (chromatographic grade) and inserted via direct injection $(10 \mu \mathrm{L})$, using nitrogen as the nebulization and desolvation gas. The capillary voltage values and cone extractor were optimized for each sample. The MS/MS experiments were performed using argon as collision gas: collision energy was 25-35 eV for saponins and 40-70 eV for OGSA. For equipment operation and collection and processing of data, Masslynx 3.3 software was used (Micro Mass).

2.3. Parasite and Macrophage Cultures. Promastigote forms of Leishmania amazonensis (MHOM/BR/75/Josefa) were cultivated at $25^{\circ} \mathrm{C}$ in Warren's medium, consisting of brain-heart infusion medium and $10 \mu \mathrm{g} / \mathrm{mL}$ each of hemin and folic acid (pH 7.2), plus 10\% inactivated fetal bovine serum (FBS; Gibco Invitrogen, New York, NY, USA). The macrophage lineage (J774A1) was maintained in RPMI 1640 medium (Gibco Invitrogen Co., Grand Island, NY, USA) with L-glutamine and $10 \% \mathrm{FBS}$, at $37^{\circ} \mathrm{C}$ in an atmosphere containing $5 \% \mathrm{CO}_{2}$.

2.4. In Vitro Antiproliferative Assays. A suspension containing $1 \times 10^{6}$ parasites $/ \mathrm{mL}$ of promastigote forms in the logarithmic phase of growth was added in 24-well culture microplates with increasing concentrations of OGSA, SAP, and EHA (10, $50,100,250$, and $500 \mu \mathrm{g} / \mathrm{mL}$ ) previously solubilized in dimethyl sulfoxide (DMSO) at a final concentration of $0.5 \%$ in all tests. For $72 \mathrm{~h}$, these protozoa were maintained at $25^{\circ} \mathrm{C}$ in Warren's medium supplemented with 10\% FBS. Antileishmanial activity was determined by directly counting freeliving parasites in a Neubauer chamber to find the concentration that inhibited $50 \%\left(\mathrm{IC}_{50}\right)$ and $90 \%\left(\mathrm{IC}_{90}\right)$ of the parasite growth compared to untreated control cells.

Antileishmanial activity assays against intracellular amastigote forms were performed according to methods described by Kaplum et al. [16]. Briefly, peritoneal macrophages were isolated from $\mathrm{BALB} / \mathrm{c}$ mice by washing the peritoneal cavity with cold phosphate-buffered saline (PBS) supplemented with 3\% FBS (protocol number 029/2014 approved by the Ethical Committee of the State University of Maringa). A suspension of $5 \times 10^{5}$ macrophages $/ \mathrm{mL}$ was plated in a 24 -well microplate and incubated for $2 \mathrm{~h}$ at $37^{\circ} \mathrm{C}$ in a $5 \% \mathrm{CO}_{2}$ atmosphere. These cells were infected with promastigote forms in the stationary growth phase at a 7:1 parasite: macrophage ratio for $4 \mathrm{~h}$ at $34^{\circ} \mathrm{C}$ and $5 \% \mathrm{CO}_{2}$. Afterwards, the infected macrophages were treated with OGSA, SAP, or EHA $(1,5,10$, 50 , and $100 \mu \mathrm{g} / \mathrm{mL}$ ) and incubated for $48 \mathrm{~h}$. The number of intracellular amastigotes was counted under a light microscope after Giemsa staining, in at least 200 macrophages for each condition.

2.5. In Vitro Cytotoxicity and Hemolysis Assays. J774A1 macrophage cells $\left(5 \times 10^{5}\right.$ cells $\left./ \mathrm{mL}\right)$ were added to each well in 96-well microplates and incubated in a $5 \% \mathrm{CO}_{2}$ atmosphere at $37^{\circ} \mathrm{C}$ to obtain a macrophage monolayer. Increasing concentrations of OGSA $(1,5,10,50,100,250$, or $500 \mu \mathrm{g} / \mathrm{mL})$ were added and incubated for $48 \mathrm{~h}$ in the same conditions. A colorimetric MTT method was applied to verify cell viability through the metabolization of MTT (3-[4,5-dimethylthiazol2-yl]-2,5-diphenyltetrazolium bromide formazan; $2 \mathrm{mg} / \mathrm{mL}$ ) to purple formazan crystals after $4 \mathrm{~h}$ of incubation in the dark. DMSO was used to solubilize formazan to facilitate analysis on a microplate reader (Bio-Tek Power Wave XS) at $570 \mathrm{~nm}$ 
[17]. The percentage of viable macrophages was calculated compared to the untreated cells and the concentration that resulted in $50 \%$ cell viability of the macrophages $\left(\mathrm{CC}_{50}\right)$ was determined.

Human blood (type $\mathrm{A}+$ ) was defibrinated using glass beads and a 6\% erythrocyte suspension was prepared in PBS. Plant extracts and fractions were added to the erythrocyte suspension in a 96-well microplate $(10,50,100,500$, or $1000 \mu \mathrm{g} / \mathrm{mL}$ ) and incubated for $3 \mathrm{~h}$ at $37^{\circ} \mathrm{C}$. Next, the plates were centrifuged for $3 \mathrm{~min}$ at $1200 \mathrm{rpm}$, and $100 \mu \mathrm{L}$ of the supernatant was transferred to another sterile 96-well plate to read the absorbance at $550 \mathrm{~nm}$ in a microplate reader (BioTek, model Power Wave XS). The nonionic surfactant Triton $\mathrm{X}-100$ (1\%), known to rupture lipid membranes, was used as positive control, and the negative control was a suspension of untreated red blood cells. This method measured hemoglobin release due to hemolysis.

2.6. Scanning Electron Microscopy. After treatment for $72 \mathrm{~h}$ at the $\mathrm{IC}_{50}$ or $\mathrm{IC}_{90}$ of OGSA, cells were fixed with $2.5 \%$ glutaraldehyde in $0.1 \mathrm{M}$ cacodylate buffer for $3 \mathrm{~h}$. Next, the cells were adhered to poly-L-Lysine coated plates, which were dehydrated in increasing percentages of ethanol from 30\% to $100 \%$. The samples were critical-point-dried in $\mathrm{CO}_{2}$ and then coated with gold alloy. The analysis was performed on a Shimadzu SS-550 scanning electron microscope to evaluate possible morphological alterations in the cell surfaces upon OGSA treatment [18].

2.7. Transmission Electron Microscopy. Promastigote samples were treated with the $\mathrm{IC}_{50}$ or $\mathrm{IC}_{90}$ of OGSA for $72 \mathrm{~h}$ at $25^{\circ} \mathrm{C}$. Fixed samples were postfixed in a solution containing $1 \%$ osmium tetroxide, $5 \mathrm{mM}$ calcium chloride, and $0.8 \%$ potassium ferrocyanide. At the end of this process, these parasites were dehydrated in graded acetone, embedded with epoxy resin, and then polymerized at $60^{\circ} \mathrm{C}$. Ultrathin sections were obtained and stained with 5\% uranyl acetate and lead citrate and observed on JEOL JEM 1400 transmission electron microscope to analyze ultrastructural cell aspects [18].

2.8. Determination of Parasite Cell Volume by Flow Cytometry. Promastigote forms were treated with OGSA $(100,450$, or $900 \mu \mathrm{g} / \mathrm{mL}$ ) for $24 \mathrm{~h}$ at $25^{\circ} \mathrm{C}$. These treated parasites were analyzed using a BD FACSCalibur flow cytometer and 10,000 events were interpreted by CellQuest Pro software, using forward scatter (FSC) as a parameter. Histograms were analyzed considering the median point. Actinomycin D (SigmaAldrich), a known antineoplasic drug that induces apoptosis, and consequently reduces cell volume, was used as a positive control $[19,20]$.

2.9. Determination of Mitochondrial Transmembrane Potential $(\Delta \Psi \mathrm{m})$ by Flow Cytometry. Promastigote forms were treated with OGSA at 100,450 , or $900 \mu \mathrm{g} / \mathrm{mL}$ for $24 \mathrm{~h}$ at $25^{\circ} \mathrm{C}$ and incubated with $1 \mu \mathrm{L}$ ( $5 \mathrm{mg} / \mathrm{mL}$ in ethanol) rhodamine 123 (Rh 123; Sigma-Aldrich, St. Louis, MO, USA) for $15 \mathrm{~min}$. Parasites treated with the protonophore carbonyl cyanide 3-chlorophenylhydrazone (CCCP; Sigma-Aldrich; $100.0 \mu \mathrm{M}$ ) were used as a positive control. CCCP is a known mitochondrial uncoupler that allows proton transportation to the mitochondrial matrix, causing mitochondrial transmembrane potential depolarization [21]. Ten thousand events were analyzed using a BD FACSCalibur flow cytometer, and the data were analyzed on CellQuest Pro software [22]. Parasites exhibiting mitochondrial depolarization were represented in a histogram, using FL-2 as a parameter.

2.10. Detection of Phosphatidylserine Exposure by Flow Cytometry. Double staining for annexin-V-fluorescein isothiocyanate (FITC) and propidium iodide (PI) was performed using an annexin-V apoptosis detection kit according to the manufacturer's instructions. Briefly, untreated and OGSAtreated parasites $\left(100,450\right.$, or $900 \mu \mathrm{g} / \mathrm{mL}$ for $24 \mathrm{~h}$ at $\left.25^{\circ} \mathrm{C}\right)$ were resuspended in $500 \mu \mathrm{L}$ binding buffer $(140 \mathrm{mM} \mathrm{NaCl}$, $5 \mathrm{mM} \mathrm{CaCl}_{2}$, and $10 \mathrm{mM}$ HEPES-Na, $\mathrm{pH} 4.7$ ), and $5 \mu \mathrm{L}$ of FITC-conjugated Annexin-V was added. The labeled parasites were maintained at $25^{\circ} \mathrm{C}$ in the dark for $5 \mathrm{~min}$. To complete the double staining, $400 \mu \mathrm{L}$ of binding buffer plus $50 \mu \mathrm{L}$ PI were added. Fluorescence of 10,000 events was analyzed on a BD FACSCalibur cytometer and results were interpreted by CellQuest Pro software, using FL-1 and FL-2 parameters. Miltefosine, an antineoplasic drug that induces autophagy, was used as a positive control [23]. Late apoptotic processes were represented by PI-positive parasites in upper quadrants and apoptotic processes by FITC fluorescence in upper and lower-right quadrants [24].

2.11. Statistical Analysis. In the cellular experiments, the results were expressed as the mean and standard deviation of at least three independent experiments. A Student's $t$-test was performed, and $p$ values less than 0.05 were regarded as significant.

2.12. Ethics Statement. For the hemolytic assay, blood was obtained from healthy volunteer donors according to the Declaration of Helsinki (Ethical principles for medical research involving human subjects) last reviewed in 2008. The donors received an explanation about the purpose of the study and provided their written consent before blood collection. The blood was collected by brachial vein puncture by a trained professional with appropriate material and medical support. All procedures were conducted as described in specific protocol approved by the "Comitê de Ética em Pesquisa com Seres Humanos of the Universidade Estadual de Maringá" (acceptance 293/2006 COPEP-UEM). For the assays that involved mice macrophages, BALB/c mice were obtained from the Central Animal Facility of the Universidade Estadual de Maringá. All procedures were carried out in accordance with the guidelines established by the Committee on Ethics of Animal Experiments of the Universidade Estadual de Maringá, as stated in the detailed protocol approved for this experiment (acceptance 029/2014).

\section{Results}

3.1. Characterization of EHA, SAP, and OGSA Fractions. EHA, OGSA, and SAP solutions in methanol were inserted 
TABLE 1: Cytotoxic and antiparasitic effect of S. saponaria L. on J774A1 macrophages and L. amazonensis forms, respectively.

\begin{tabular}{lcccc}
\hline $\begin{array}{l}\text { S. saponaria } \\
\text { samples }\end{array}$ & $\begin{array}{c}\text { Cytotoxicity } \\
\mathrm{CC}_{50}(\mu \mathrm{g} / \mathrm{mL})\end{array}$ & $\begin{array}{c}\mathrm{IC}_{50} \text { intracellular } \\
\text { amastigotes }(\mu \mathrm{g} / \mathrm{mL})\end{array}$ & $\begin{array}{c}\text { SI } \\
\text { intracellular } \\
\text { amastigotes }\end{array}$ & $\begin{array}{c}\mathrm{IC}_{50} \text { promastigotes } \\
(\mu \mathrm{g} / \mathrm{mL})\end{array}$ \\
\hline EHA & $81.66 \pm 2.88$ & $181 \pm 8.12$ & 0.45 & $153.70 \pm 3.20$ \\
OGSA & $383.33 \pm 14.43$ & $52.11 \pm 7.63$ & 0.14 & $100.92 \pm 1.56$ \\
SAP & $2.00 \pm 0.7$ & $13.98 \pm 1.43$ & $25.41 \pm 2.88$ \\
\hline
\end{tabular}

via direct injection into the mass spectrometer in negative mode, resulting in mass spectra similar to those obtained by Murgu \& Rodrigues-Filho (2006). In the mass spectrum of EHA, peaks were observed from $\mathrm{m} / \mathrm{z}$ of $400-1550$. The region of acyclic sesquiterpene oligoglycosides was formed by intense peaks from $m / z 1100-1550$, and each peak was separated by $42 \mathrm{Da}$ (equivalent to repeated losses $\mathrm{COCH}_{2}$ ). The region of saponins contained less intense peaks from $\mathrm{m} / z$ of 650-1000, and some peaks were also separated by $42 \mathrm{Da}$.

In the OGSA mass spectrum, there was a prevalent presence of peaks above $m / z$ values of 1100 , confirming the enrichment of the OGSA fraction with acyclic sesquiterpene oligoglycosides. The same result applied to the mass spectrum of the SAP fraction, in which the extensive presence of peaks below the $\mathrm{m} / z$ of 1100 was observed, confirming the enrichment of the SAP fraction with saponins.

A peak from each spectrum of the fractions $(\mathrm{m} / z 1187$ of OGSA and $m / z 923$ of SAP) was selected for MS/MS experiments. Data provided by MS/MS confirmed the structure of the glycosides, as the sequence and molecular weight of sugars and number and types of acyl groups were linked to the substance. Data fragmentation of the ion $\mathrm{m} / \mathrm{z} 1187$ and $\mathrm{m} / \mathrm{z}$ 923 agreed with the fragmentation pattern of the reference substances, according to data obtained by Murgu (2002) in S. saponaria L., Wong et al. (1991) in Sapindus delavayi, and Kasai et al. (1986) in Sapindus mukorossi.

3.2. Activity against L. amazonensis Forms, Cytotoxicity, and Hemolysis. EHA, OGSA, and SAP dose-dependently inhibited promastigote forms during $72 \mathrm{~h}$ of treatment, exhibiting $\mathrm{IC}_{50}$ values of $153.70 \pm 3.20,100.92 \pm 1.56$, and $25.41 \pm$ $2.88 \mu \mathrm{g} / \mathrm{mL}$, and $\mathrm{IC}_{90}$ of $436.09 \pm 4.81,450.00 \pm 0.01$, and $52.18 \pm 0.64$, respectively (Figure 1 ).

For intracellular amastigote forms, EHA, OGSA, and SAP exhibited $\mathrm{IC}_{50}$ values of $181 \pm 8.12,52.11 \pm 7.63$, and $13.98 \pm 1.43 \mu \mathrm{g} / \mathrm{mL}$, respectively. The cytotoxicity for the macrophages and intracellular parasites was compared using the selectivity index (SI), which was determined by the ratio of the cytotoxic concentration 50\% $\left(\mathrm{CC}_{50}\right)$ for the J774A1 macrophages and $\mathrm{IC}_{50}$ for amastigotes (Table 1).

If SI values are higher than 1.0, the sample tested is selective for L. amazonensis promastigotes, since the concentration of drug required to decrease protozoa viability is lower than that needed to destroy the mammalian cells. Among the samples of S. saponaria L., only the OGSA fraction was selective for the parasite.

Hemolytic activity differed among OGSA, EHA, and SAP. When tested at $100 \mu \mathrm{g} / \mathrm{mL}$ (a value close to the OGSA $\mathrm{IC}_{50}$ ),

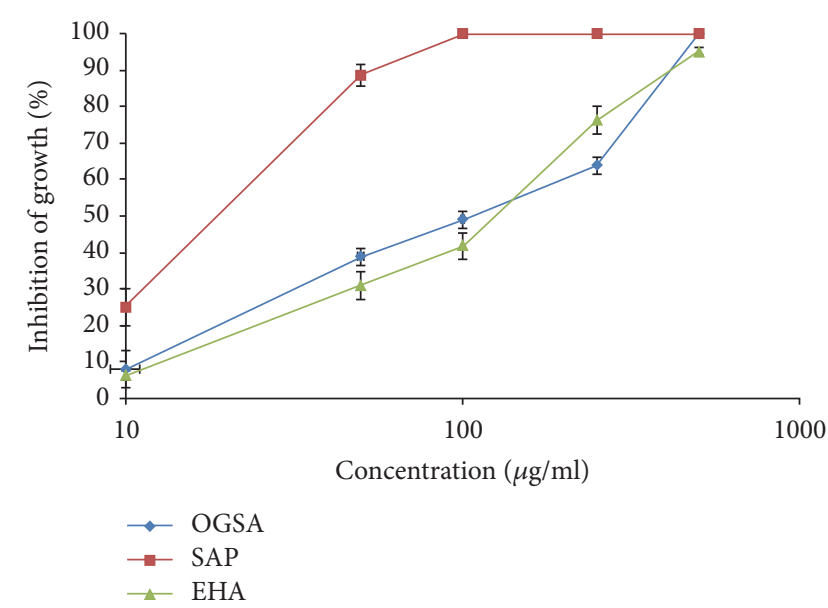

FIGURE 1: Effect of OGSA, SAP, and EHA on L. amazonensis promastigote forms after incubation of parasite for $72 \mathrm{~h}$ with 10,50 , 100,250 , and $500 \mu \mathrm{g} / \mathrm{mL}$.

test drugs showed 0, $22.51 \pm 1.07$, and $100 \%$ of hemolysis for OGSA, EHA, and SAP, respectively. At the highest concentration tested $(1000 \mu \mathrm{g} / \mathrm{mL})$, the OGSA fraction treatment resulted in only $34.52 \pm 3.99 \%$ hemolysis, while EHA and SAP treatment elicited $95.37 \pm 1.12 \%$ and $100 \%$ hemolytic erythrocytes, respectively.

3.3. Morphological and Ultrastructural Alterations in L. amazonensis Caused by the OGSA Fraction. Owing to the promising results presented by OGSA, parasites treated with OGSA were subjected to electron microscopy (SEM), which revealed morphological alterations in the promastigote forms of $L$. amazonensis. Untreated microorganisms showed standard characteristics such as elongated shape, typical size, and a single flagellum. OGSA treatment modified the shape and size of the cell body, and twisted the flagellum, mainly in parasites treated at the $\mathrm{IC}_{90}(450 \mu \mathrm{g} / \mathrm{mL})$ of OGSA (Figure 2). Moreover, important unevenness on the cell membrane was observed in the SEM micrographs (Figures 2(b) and $2(\mathrm{~d}))$, although there were no signs of cytoplasmic content extravasation.

Flow cytometry was used to confirm the increased cell volume in promastigote forms revealed by SEM. Flow cytometry histograms showed that OGSA-treated parasites exhibited increased parasite volume (Figures 3(a) and 3(b)). Initially, a dose-dependent increase in cell volume was observed (32.15 and $76.23 \%$, at OGSA concentrations of 100 and $450 \mu \mathrm{g} / \mathrm{mL})$. However, treatment with the highest OGSA 


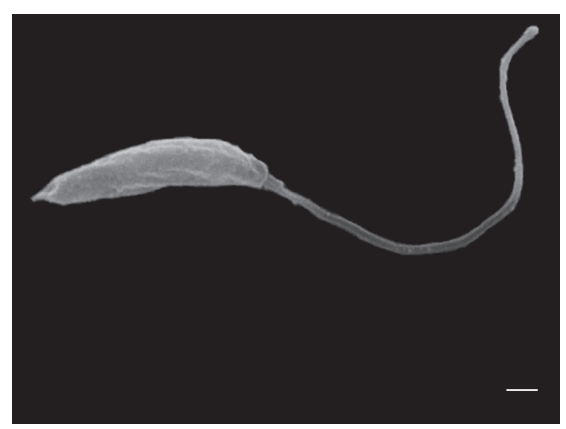

(a)

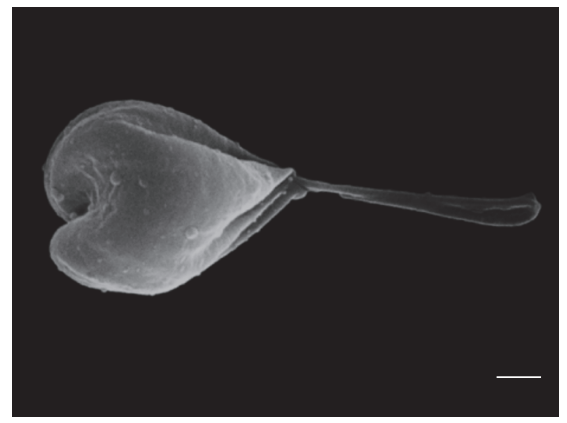

(d)

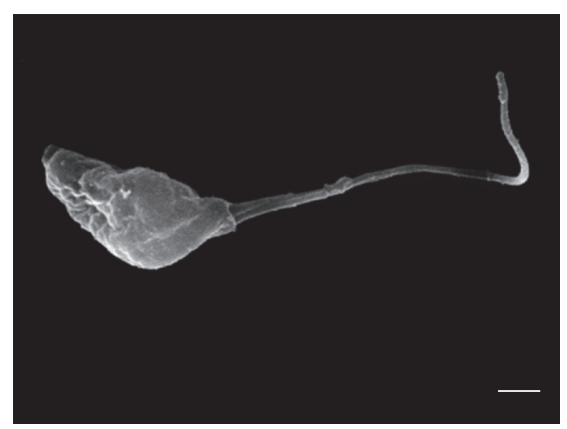

(b)

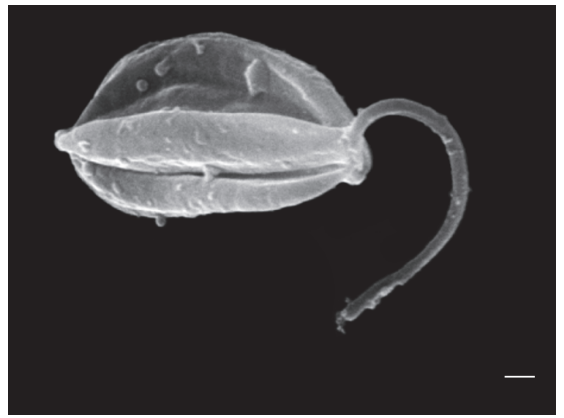

(e)

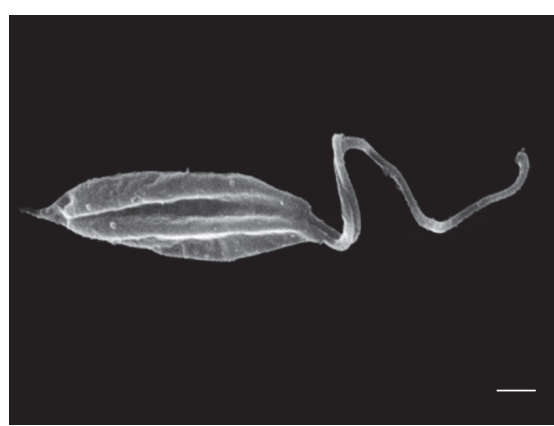

(c)

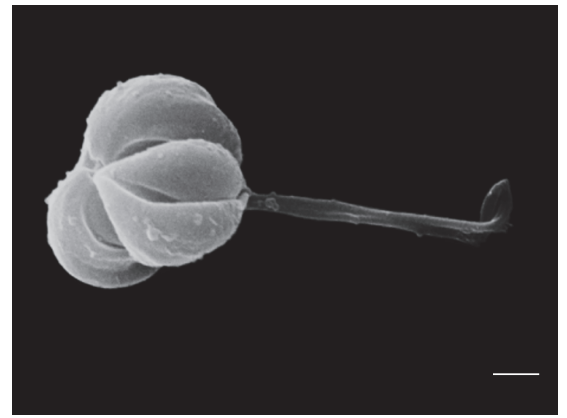

(f)

FIGURE 2: Scanning electron microscopy of promastigotes of L. amazonensis treated for $72 \mathrm{~h}$ with OGSA. (a) Untreated parasites have a typical elongated morphology. ((b) and (c)) Parasites treated with $100 \mu \mathrm{g} / \mathrm{mL}$ of OGSA show morphological changes as cell body deformation, twisting of the flagellum, and reticent increase in volume. ((d) to (f)) Parasites treated with $450 \mu \mathrm{g} / \mathrm{mL}$ OGSA exhibit more pronounced morphological changes. Scale bar $=1 \mu \mathrm{m}$.

concentration $(900 \mu \mathrm{g} / \mathrm{mL})$ decreased cell volume by $28.75 \%$, probably due to early apoptotic processes induced by the high drug concentration (Figure 3(c)).

Transmission electron microscopy (TEM) of OGSAtreated promastigotes also indicated the presence of ultrastructural alterations (Figure 4). OGSA induced damage in parasite mitochondria, which presented disorganized features and the presence of inner concentric membrane structures. Extensive cytoplasmic vacuolization (Figure 4(e)) and general disorganization of the organelles (Figure 4(f)), mainly related to the endoplasmic reticulum (Figures 4(b), $4(\mathrm{e})$, and $4(\mathrm{~g})$ ), were important changes caused by OGSA treatment. Alterations in the nucleus, number of flagella, or cytoplasmic membrane were not found by TEM analysis.

\subsection{Alteration of Mitochondrial Transmembrane Potential} $(\triangle \Psi \mathrm{m})$. TEM demonstrated that OGSA treatment altered parasite mitochondria, and the $\Delta \Psi \mathrm{m}$ was evaluated by flow cytometry using Rh 123, which accumulates inside healthy mitochondria. The histograms revealed a decrease in total Rh 123 fluorescence intensity upon OGSA treatment, demonstrating that Rh 123 was not inside the mitochondria, probably due to mitochondrial membrane depolarization. OGSA at concentrations of 100,450 , and $900 \mu \mathrm{g} / \mathrm{mL}$ caused 46.23 , 60.04, and $75.63 \%$ decreases in total $\mathrm{Rh} 123$ fluorescence intensity, respectively, compared with the gray area, representing the untreated control cells (Figure 5).
3.5. Induction of Phosphatidylserine Exposure. Phosphatidylserine (PS) is a phospholipid that, under normal biochemical conditions, remains on the inner face of the plasma membrane or cytosolic face. During the apoptotic process, these molecules are translocated to the cell surface, working as a signal to be phagocytosed from defense cells. Annexin-V has an affinity for phosphatidylserine and the fluorescence emitted from FITC conjugated to annexin-V suggests apoptotic or late apoptotic processes if propidium iodide fluorescence is negative or positive, respectively. The typically labeled parasites appeared at the upper and lowerright quadrants on the dot-plot graphic. The intensity of annexin-V and PI fluorescence was increased up to $78.40 \%$ compared to intensity of untreated parasites, suggesting a late apoptotic process (Figure 6). Annexin-V-FITC was able to link to the phosphatidylserine on the inner face of the cell membrane, indicating the loss of membrane integrity, which can be observed by the PI fluorescence.

\section{Discussion}

Current treatments for leishmaniasis are unsatisfactory because the parasite is also a eukaryotic organism and shares many features with its mammalian cell hosts [25]. Moreover, there has been an increase in the number of cases resistant to the available drugs recommended for treating cutaneous and visceral leishmaniasis. It is imperative to search for new, effective, safe, low-cost agents to replace the current ones [26]. 


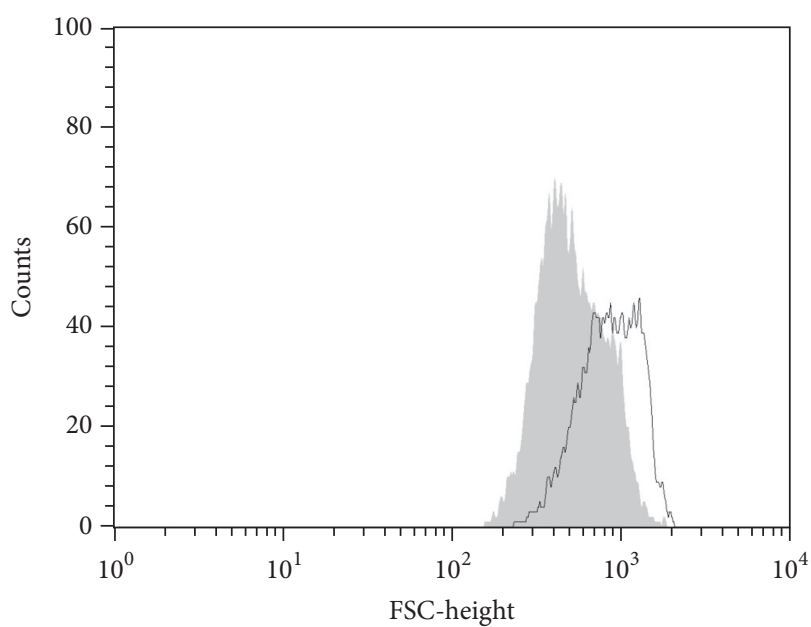

(a)

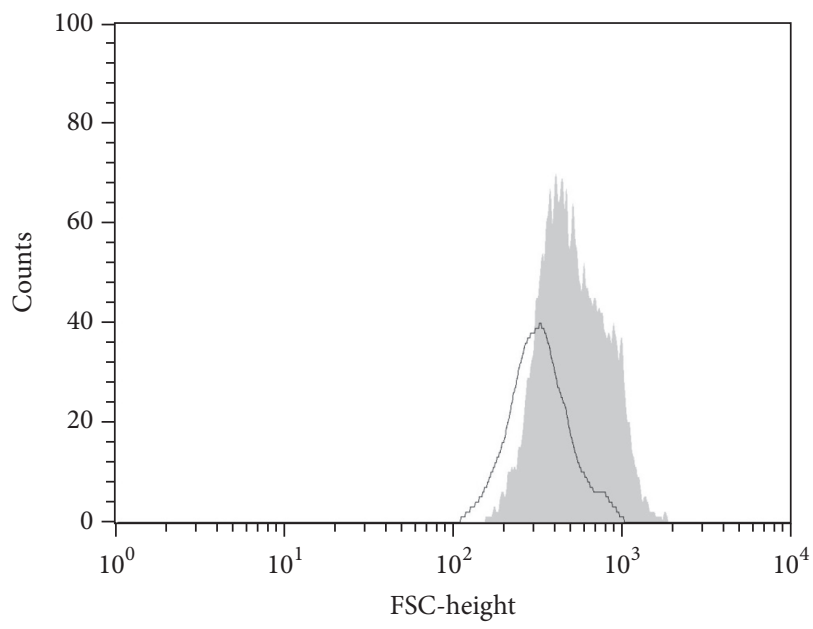

(c)

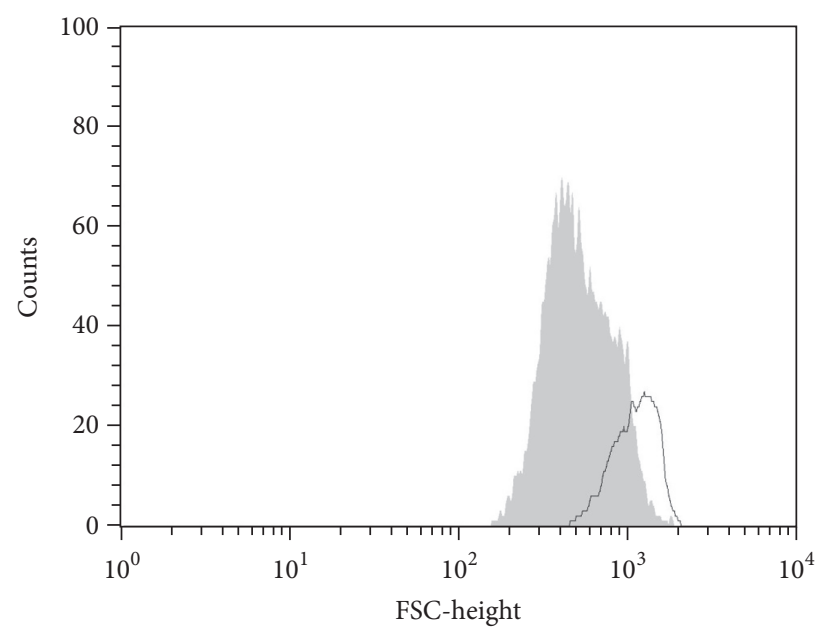

(b)

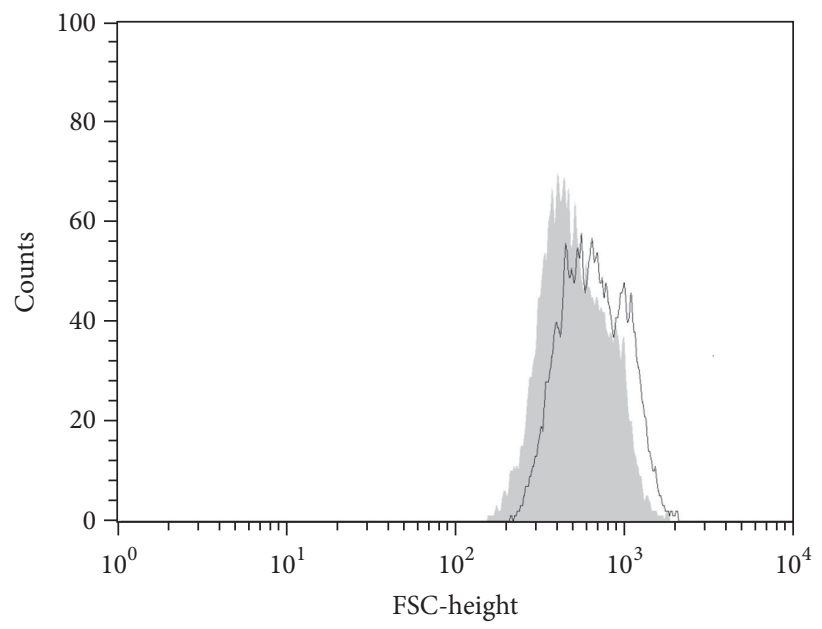

(d)

FIGURE 3: Cell volume of L. amazonensis promastigotes treated with OGSA fraction at concentrations of $100 \mu \mathrm{g} / \mathrm{mL}$ (a), $450 \mu \mathrm{g} / \mathrm{mL}$ (b), and $900 \mu \mathrm{g} / \mathrm{mL}$ (c) and with Actinomycin D (positive control) (d). The gray area corresponds to the untreated control cells.

The use of plants as medicine involves the investigation of active compounds, starting with the isolation of morphine from opium in the 19th century $[27,28]$. Methods such as fractionation, enrichment of certain substances, isolation, and characterization of pharmacologically relevant compounds from medicinal plants are currently being applied. In addition, drug research techniques have been used to standardize herbal formulations and elucidate their compounds considered as analytical markers [29].

In the present study, EHA, SAP, and OGSA exhibited antiproliferative effects on promastigotes and intracellular amastigotes, along with reduced survival of intracellular parasites in macrophages. However, OGSA was the only fraction more selective for the protozoan than for mammalian cells, and at $100 \mu \mathrm{g} / \mathrm{mL}$, close to its $\mathrm{IC}_{50}$ for promastigotes, did not show any degree of hemolysis. In contrast, the hemolytic activity of SAP was present even at low concentrations, as expected. Saponins are known to disrupt erythrocytes by interacting with sterols on erythrocyte membranes, increasing cell permeability and causing hemoglobin loss [30].
For these reasons, OGSA was selected and subjected to additional investigations to study the effects of this compound on promastigote forms of L. amazonensis.

OGSA acted like an antileishmanial substance by affecting the parasite's mitochondrial function even at lower concentrations, according to the variations in mitochondrial transmembrane potential $(\Delta \Psi \mathrm{m})$, shown from flow cytometry experiments using $\mathrm{Rh} 123$. This potential $(\Delta \Psi \mathrm{m})$ refers to the electrochemical gradient generated by the passage of electrons through complexes I to IV of the respiratory chain, resulting in the accumulation of protons between the external and internal mitochondrial membranes. The return of these protons to the mitochondrial matrix through complex $\mathrm{V}$ allows the phosphorylation of ADP to ATP, the main cellular energy source [31]. Rhodamine 123 accumulates in an inverse proportion to $\Delta \Psi \mathrm{m}$, and it may be an indicator of cell damage. Maintaining transmembrane potential is essential for parasite survival [32].

Flow cytometry analysis indicated a late apoptotic process or necrosis after treatment with the higher concentration 


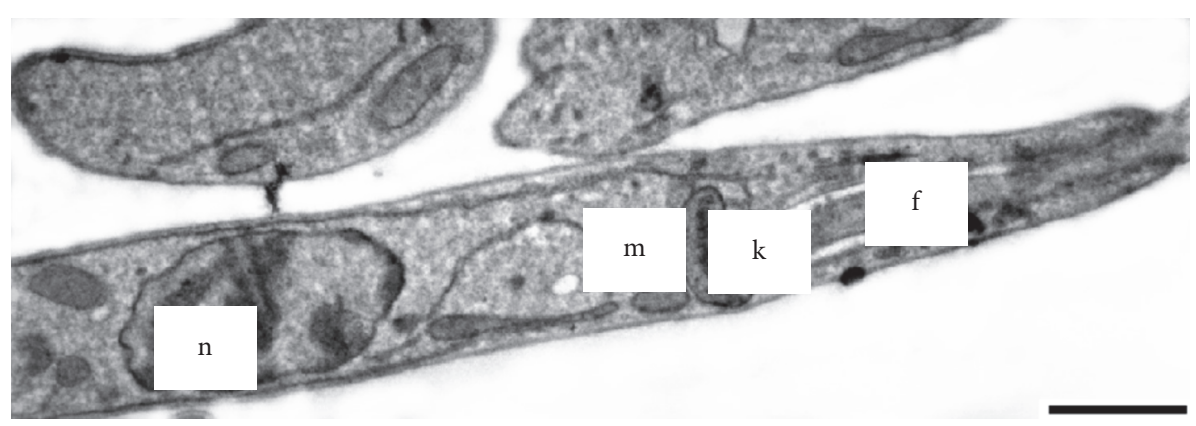

(a)

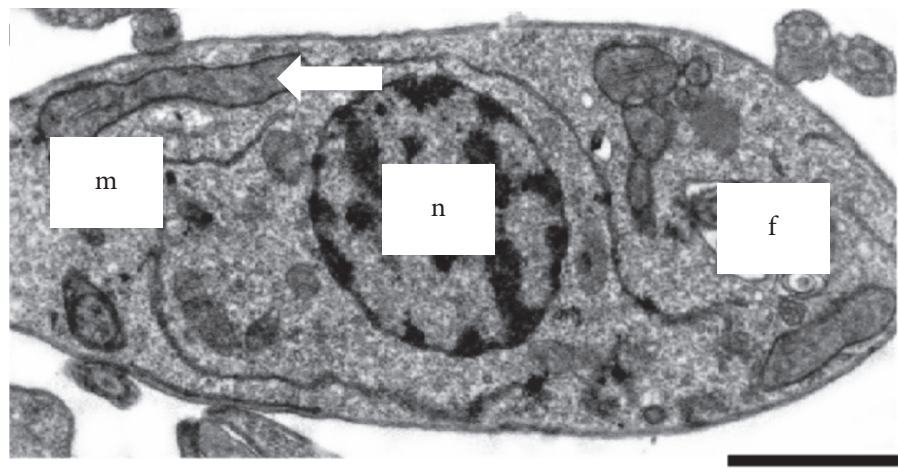

(c)

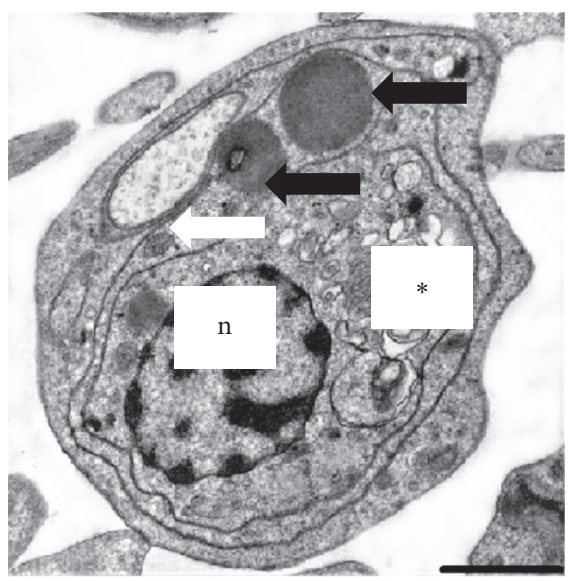

(e)

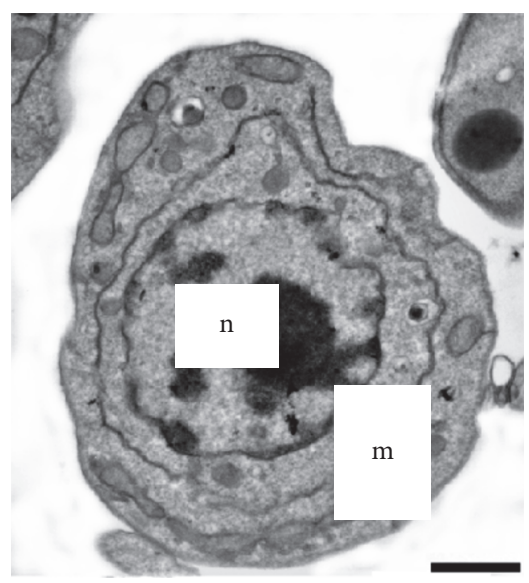

(f)

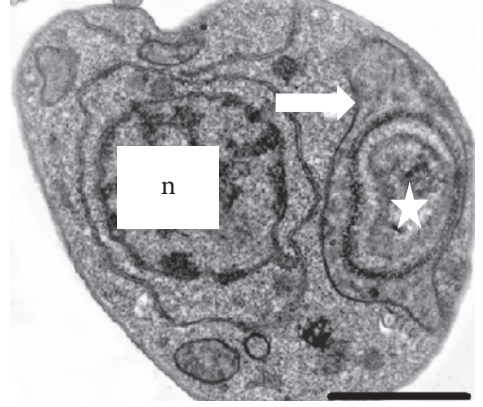

(b)

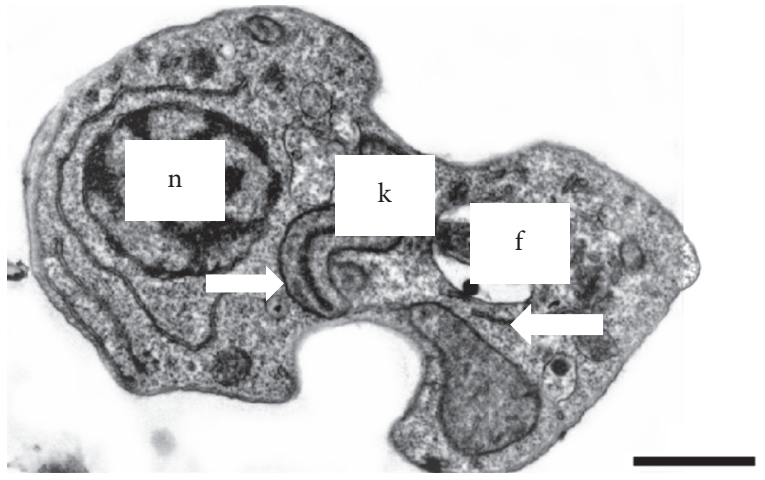

(d)

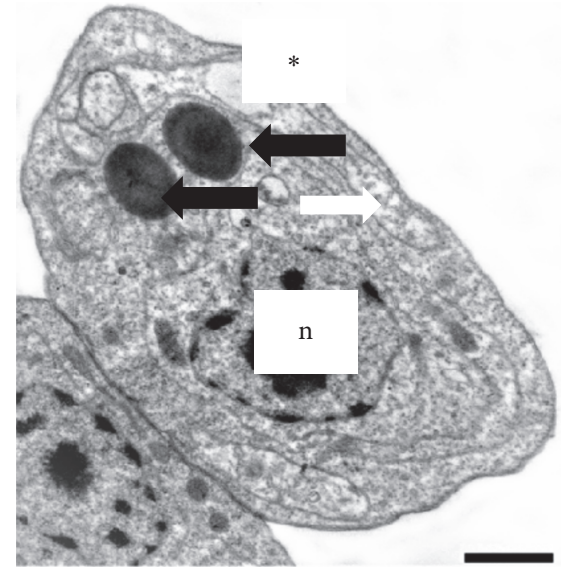

(g)

FIGURE 4: Transmission electron microscopy of L. amazonensis promastigotes treated for $72 \mathrm{~h}$ with OGSA. (a) Untreated parasites have a typical elongated morphology. ((b) to (d)) Parasites treated with $100 \mu \mathrm{g} / \mathrm{mL}$ OGSA exhibit morphological changes. ((e) to (g)) Parasites treated with $450 \mu \mathrm{g} / \mathrm{mL}$ OGSA exhibit more pronounced morphological changes. White arrows indicate swollen mitochondria, black arrows indicate lipid bodies, star indicates concentric structures within the mitochondria, and asterisks indicate vacuoles. f, flagellum; $\mathrm{m}$, mitochondria; $\mathrm{n}$, nucleus; $\mathrm{k}$, kinetoplast. Scale bar $=1 \mu \mathrm{m}$.

of OGSA. Based on flow cytometry alone, it cannot be determined which of these scenarios is occurring, since it is not possible to conclude if the necrotic process was primary or secondary [33].

Apoptotic events may precede cell death. Following the translocation of phosphatidylserine, apoptotic cells lose the integrity of their plasma membrane [34]. OGSA seems to dose-dependently induce this phenomenon, which was revealed by PI experiments. An overall analysis of the results suggests that the cellular effects of the lower concentrations of OGSA caused a mild necrotic process, a possible primary effect evidenced by cell swelling and positive PI results. Nevertheless, SEM and TEM analyses did not reveal intracellular content extravasation or decreased intracellular density.

The highest concentration of OGSA seemingly caused an opposite effect, indicated by cell shrinkage and other evidence of apoptosis, like cytoplasmic vacuolization and organelle disorganization, mainly in the mitochondria and endoplasmic reticulum, according to TEM micrographs and Rh 123 labeling, respectively [35]. These apoptotic features 


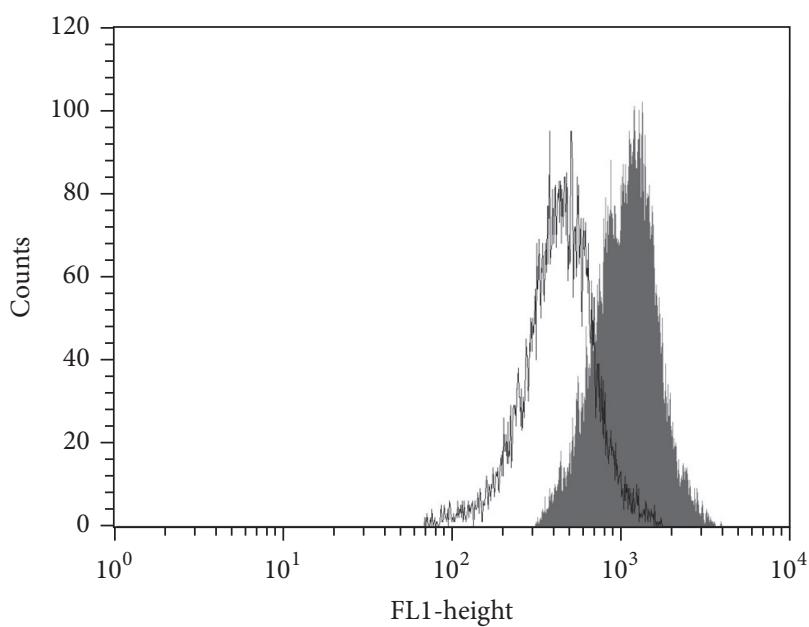

(a)

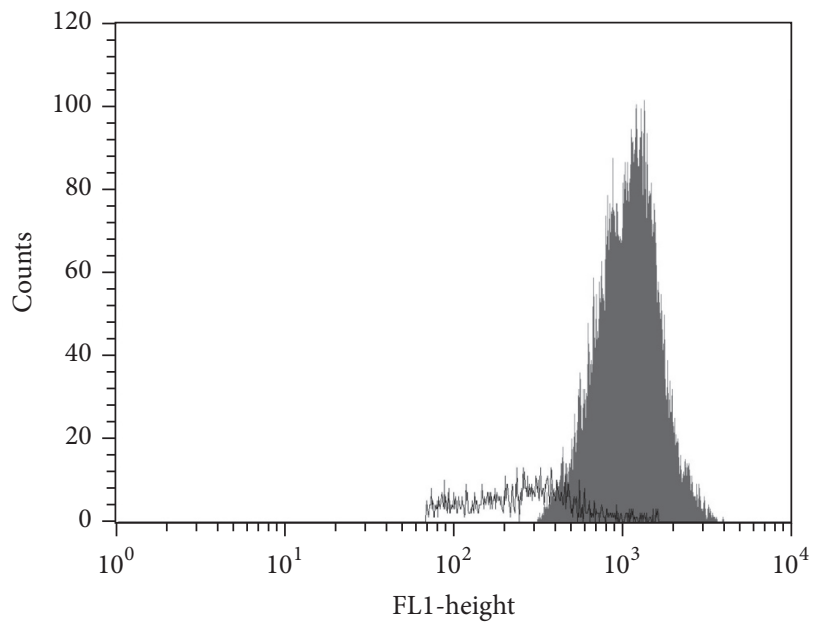

(c)

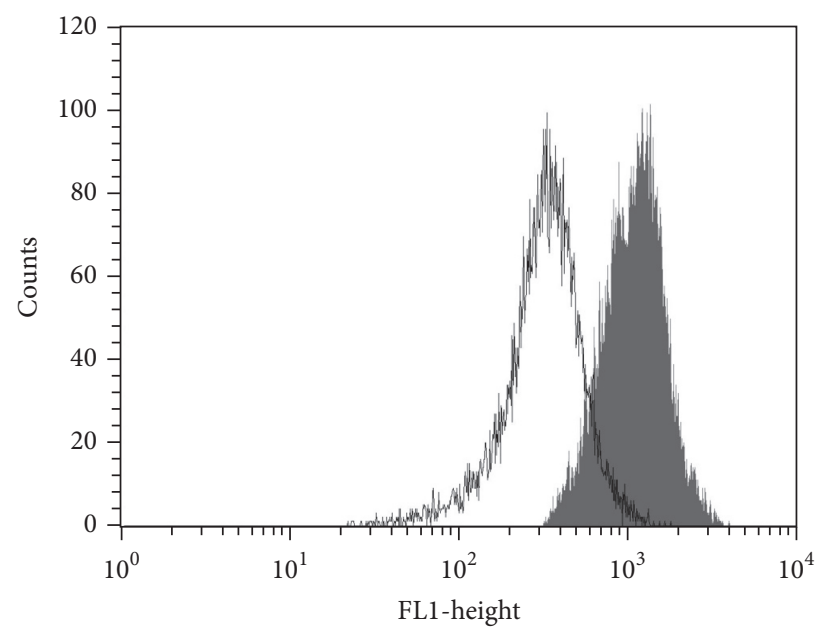

(b)

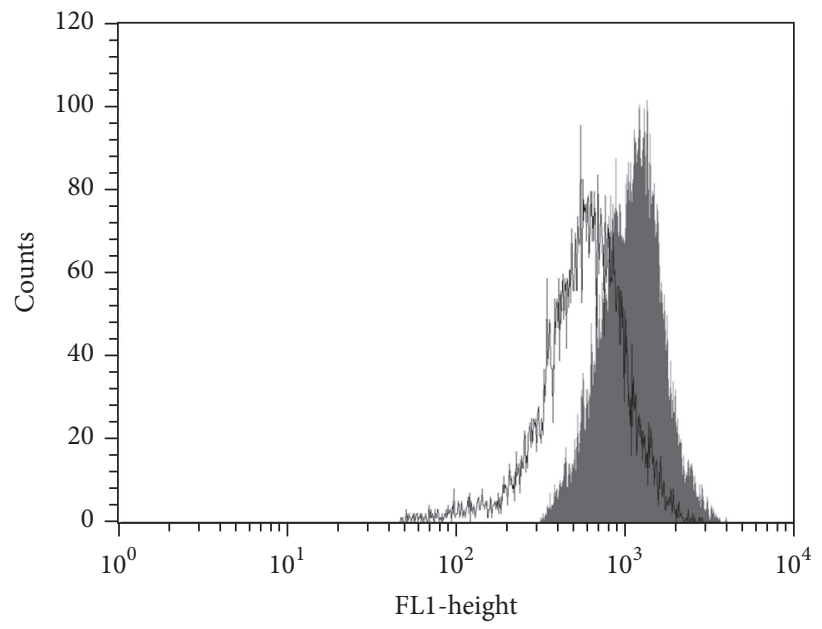

(d)

FIGURE 5: Rhodamine 123-labeled mitochondrial membrane potential assay by flow cytometry. The figure shows L. amazonensis promastigotes treated with $100 \mu \mathrm{g} / \mathrm{mL}$ (a), $450 \mu \mathrm{g} / \mathrm{mL}$ (b), and $900 \mu \mathrm{g} / \mathrm{mL}$ (c) and with CCCP (positive control) (d). The gray area corresponds to the untreated control cells.

appeared gradually and dose-dependently, eventually reaching late apoptosis and cell death by loss of cell membrane integrity, causing changes in the osmotic balance between the parasites and the environment and jeopardizing the selective permeability of the plasma membrane. These interpretations allow us to suggest that necrosis was a secondary effect from the highest concentration of OGSA treatment.

In addition, evidence of autophagy, like typical autophagosomes, was not found from TEM analysis, which is considered the gold standard to study this process [36]. However, the intense disorganization of the endoplasmic reticulum might create these structures after a longer time of OGSA exposure past $24 \mathrm{~h}$.

Other glycosides have been reported as cell death inducers in some studies; however, they always present some cyclization in their chemical structure. The acyclic sesquiterpene oligoglycosides studied in this paper do not possess any kind of cyclization but still induced cell death, which may show that their mechanism of action is distinct. Secoiridoid glycosides from Swertia chirata cause protozoa cell death by inhibiting the catalytic activity of $L$. donovani topoisomerase I [7]. A tetrasaccharide antigen found on the lipophosphoglycan membrane of the genus Leishmania may be explored using a synthetic carbohydrate-based vaccine for the treatment of leishmaniasis [37]. The quinovic acid glycosides isolated from $N$. diderrichii show strong activity against intracellular amastigotes of $L$. infantum, and the mechanism in this case was inhibition of parasite internalization in the promastigote form [8]. In addition, cardiac glycosides are exceptional inducers of immunogenic cell death, an effect that is associated with inhibition of the plasma membrane $\mathrm{Na}+/ \mathrm{K}+$ ATPase [38].

In contrast, monodesmosidic saponins, such as those present in S. saponaria L. [39], act specifically on the plasma membrane of $L$. infantum promastigotes by nonspecific interactions with the ergosterol present in these parasites. This interaction causes loss of integrity or changes the negative charge of the carbohydrate portion of cell membranes. 


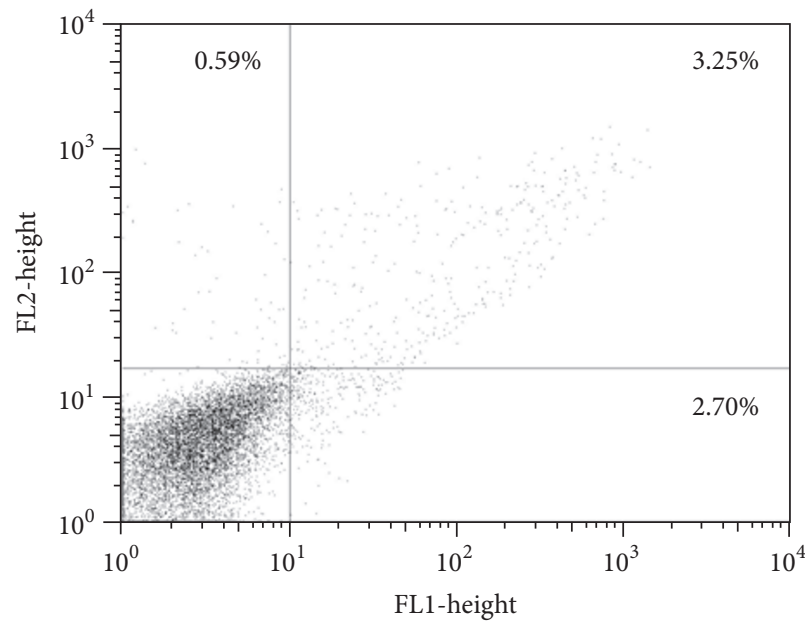

(a)

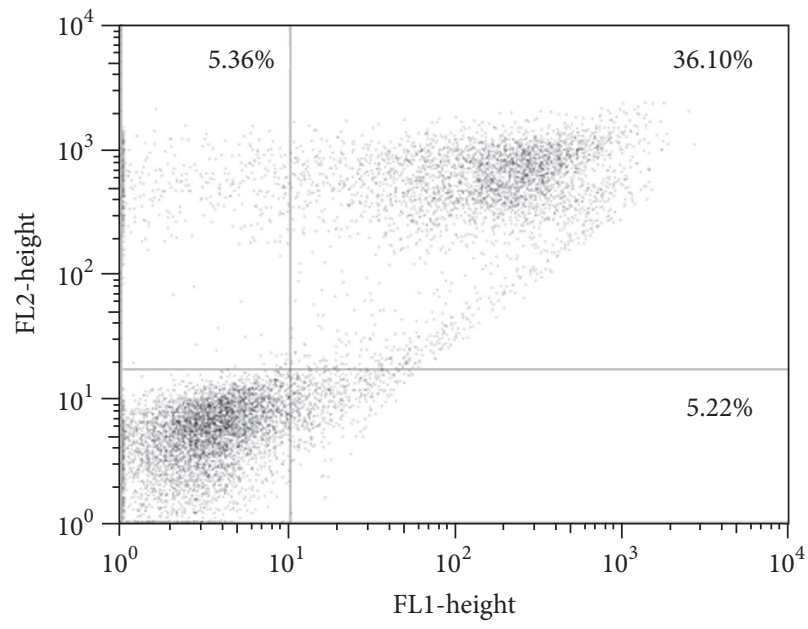

(c)

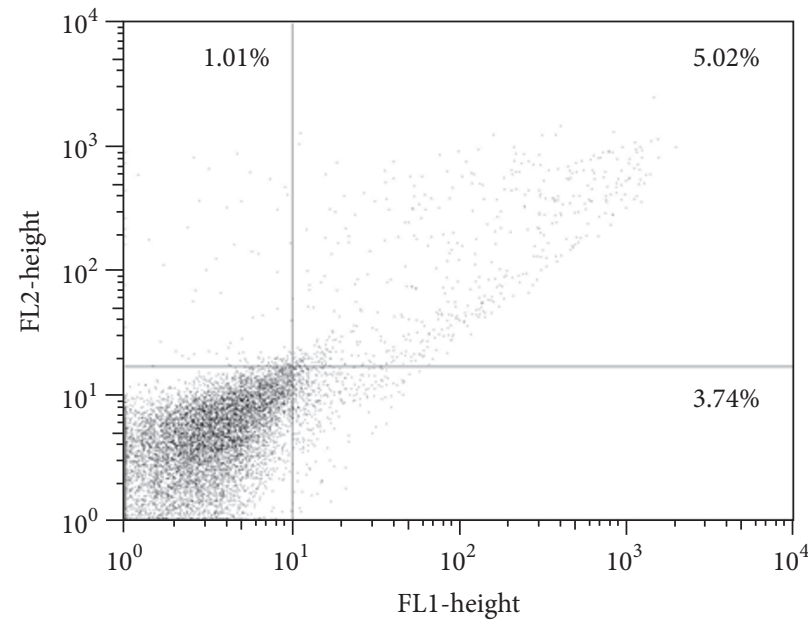

(b)

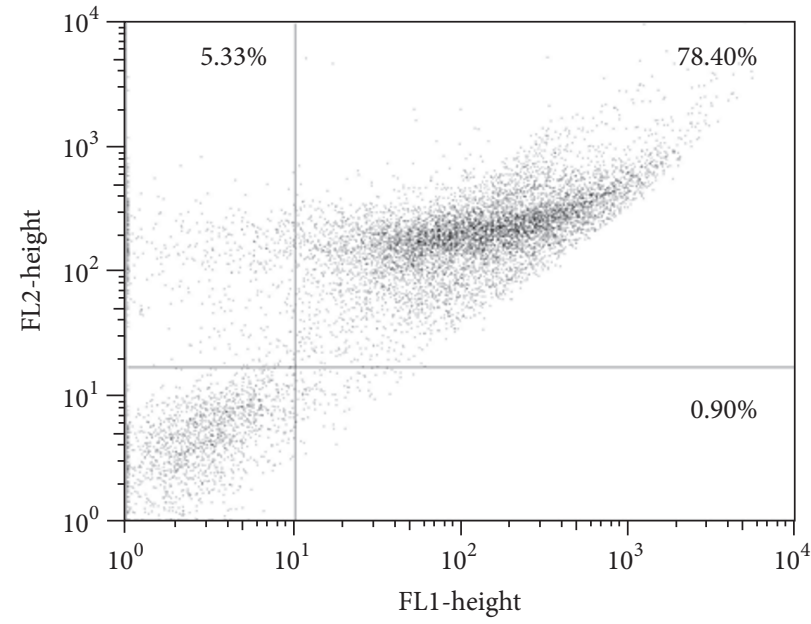

(d)

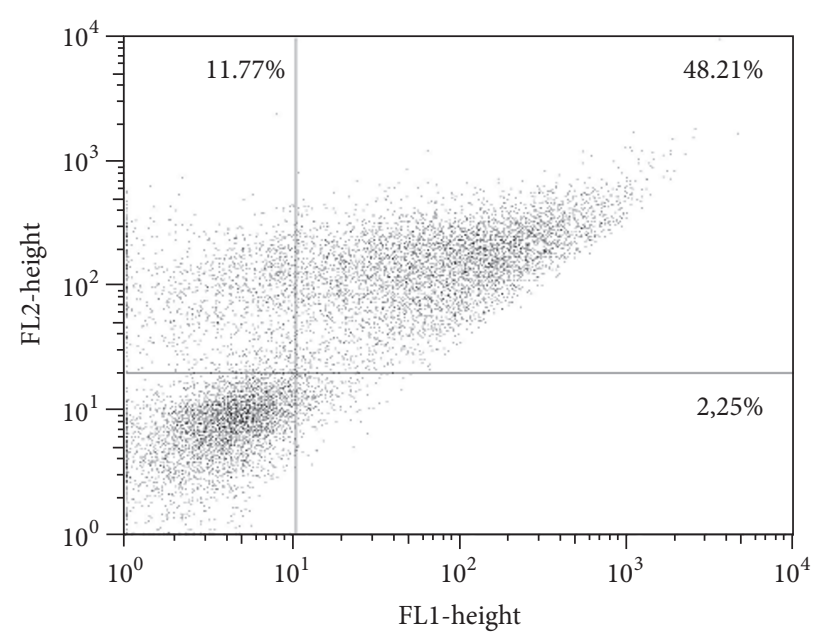

(e)

FIGURE 6: Phosphatidylserine exposure in untreated L. amazonensis promastigotes (a) and promastigotes treated with $100 \mu \mathrm{g} / \mathrm{mL}$ (b), $450 \mu \mathrm{g} / \mathrm{mL}$ (c), and $900 \mu \mathrm{g} / \mathrm{mL}$ (d) OGSA for $24 \mathrm{~h}$ using annexin-V FITC and PI. Miltefosine was used as positive control (e). 
This peculiar mechanism of action of saponins, which act exclusively on the cell membrane and their integrity to cause necrotic processes, may explain the difference between SAP and OGSA regarding their antiproliferative activity, the effects on intracellular amastigotes, and toxicity in general, since the OGSA fraction greatly affected apoptotic process and the development of cell death.

When biological activities of vegetal species are investigated, it is important to determine which plant components are responsible for the observed activity. In addition, it is important to verify if the crude extract is more or less active than its fractions. Besides the investigation of the antiprotozoal and cytotoxic activities of a given sample, it is necessary to consider other factors to elucidate the effects of compounds tested on the parasites. Thus, the search for morphological, ultrastructural, and biochemical changes is important to help determine the probable mechanism responsible for cell death.

\section{Conclusion}

Our results demonstrated inhibition of promastigote and intracellular amastigote forms of L. amazonensis from the extract and fractions of S. saponaria L. However, only the OGSA fraction was selective for different evolutionary forms of L. amazonensis and did not show hemolytic activity. OGSA induced morphological and ultrastructural alterations in promastigote forms, and these results were confirmed by cytometry assays. Thus, our findings suggest that treating with high concentrations of the OGSA fraction can have an antileishmanial effect, inducing apoptotic processes followed by necrosis.

\section{Conflicts of Interest}

All the authors declare that there are no conflicts of interest in this study.

\section{Acknowledgments}

This research was supported by Conselho Nacional de Desenvolvimento Científico e Tecnológico (CNPq), Coordenação de Aperfeiçoamento de Pessoal de Nível Superior (Capes), Financiadora de Estudos e Projetos (FINEP), Complexo de Centrais de Apoio a Pesquisa (COMCAP-UEM), and Programa de Núcleos de Excelência (PRONEX/Fundação Araucária).

\section{References}

[1] L. Lovato, B. L. Pelegrini, J. Rodrigues, A. J. Braz de Oliveira, and I. C. Piloto Ferreira, "Seed oil of Sapindus saponaria L. (Sapindaceae) as potential C16 to C22 fatty acids resource," Biomass and Bioenergy, vol. 60, pp. 247-251, 2014.

[2] O. A. A. Guirado, "Potencial medicinal del gênero SapindusL. (Sapindaceae) y de lá especie Sapindus saponariaL," Revista Cubana Planta Medicinal, vol. 10, pp. 3-4, 2005.

[3] A. Sharma, S. C. Sati, D. Sati, Maneesha, and S. K. Kothiyal, "Chemical constituents and bio activities of genus Sapindus,"
International Journal of Research in Ayurveda and Pharmacy, no. 2, pp. 403-409, 2011.

[4] M. Murgu and E. Rodrigues Filho, "Dereplication of glycosides from Sapindus saponariausing liquid cromatographymass spectrometry," Journal of the Brazilian Chemical Society, vol. 17, no. 7, pp. 1291-1290, 2006.

[5] L. Maes, D. Vanden Berghe, N. Germonprez et al., "In Vitro and In Vivo Activities of a Triterpenoid Saponin Extract (PX-6518) from the Plant Maesa balansae against Visceral Leishmania Species," Antimicrobial Agents and Chemotherapy, vol. 48, no. 1, pp. 130-136, 2004.

[6] R. A. I. da Luz, M. Vermeersch, M. Deschacht et al., "In vitro and in vivo prophylactic and curative activity of the triterpene saponin PX-6518 against cutaneous Leishmania species," Journal of Antimicrobial Chemotherapy, vol. 66, no. 2, Article ID dkq444, pp. 350-353, 2011.

[7] S. Ray, H. K. Majumder, A. K. Chakravarty, S. Mukhopadhyay, R. R. Gil, and G. A. Cordell, "Amarogentin, a naturally occurring secoiridoid glycoside and a newly recognized inhibitor of topoisomerase I from Leishmania donovani," Journal of Natural Products, vol. 59, no. 1, pp. 27-29, 1996.

[8] C. Di Giorgio, M. Lamidi, F. Delmas, G. Balansard, and E. Ollivier, "Antileishmanial activity of quinovic acid glycosides and cadambine acid isolated from Nauclea diderrichii," Planta Medica, vol. 72, no. 15, pp. 1396-1402, 2006.

[9] W. M. Abdel-Mageed, E. Y. Backheet, A. A. Khalifa, Z. Z. Ibraheim, and S. A. Ross, "Antiparasitic antioxidant phenylpropanoids and iridoid glycosides from Tecoma mollis," Fitoterapia, vol. 83, no. 3, pp. 500-507, 2012.

[10] S. A. Grevelink and E. A. Lerner, "Leishmaniasis," Journal of the American Academy of Dermatology, vol. 34, no. 2 I, pp. 257-272, 1996.

[11] O. Genaro, "Leishmaniose Tegumentar Americana," in Parasitologia Humana, D. P. Neves, Ed., pp. 41-60, Atheneu, São Paulo, Brazil, 9th edition, 1998.

[12] World Health Organization, Parasitic Disease, World Health Organization, 2015, http://www.who.int/leishmaniasis/en/index .html.

[13] F. Chappuis, E. Alirol, D. T. Worku, Y. Mueller, and K. Ritmeijer, "High mortality among older patients treated with pentavalent antimonials for visceral leishmaniasis in east africa and rationale for switch to liposomal amphotericin B," Antimicrobial Agents and Chemotherapy, vol. 55, no. 1, pp. 455-456, 2011.

[14] R. L. M. Neto, L. M. A. Sousa, C. S. Dias, J. M. B. Filho, M. R. Oliveira, and R. C. B. Q. Figueiredo, "Morphological and physiological changes in Leishmania promastigotes induced by yangambin, a lignan obtained from Ocotea duckei," Experimental Parasitology, vol. 127, no. 1, pp. 215-221, 2011.

[15] K. Seifert and S. L. Croft, "In vitroand in vivointeractions between miltefosine and other antileishmanial drugs," Antimicrobial Agents and Chemotherapy, vol. 50, no. 1, pp. 73-79, 2006.

[16] V. Kaplum, J. Cogo, D. P. Sangi, T. Ueda-Nakamura, A. G. Corrêa, and C. V. Nakamura, "In vitro and in vivo activities of 2,3-diarylsubstituted quinoxaline derivatives against Leishmania amazonensis," Antimicrobial Agents and Chemotherapy, vol. 60, no. 6, pp. 3433-3444, 2016.

[17] T. Mosmann, "Rapid colorimetric assay for cellular growth and survival: application to proliferation and cytotoxicity assays," Journal of Immunological Methods, vol. 65, no. 1-2, pp. 55-63, 1983.

[18] E. A. Britta, D. B. Scariot, H. Falzirolli et al., "Cell death and ultrastructural alterations in Leishmania amazonensis caused 
by new compound 4-Nitrobenzaldehyde thiosemicarbazone derived from S-limonene," BMC Microbiology, vol. 14, no. 1, article no. 236, 2014.

[19] D. B. Scariot, E. A. Britta, A. L. Moreira et al., "Induction of Early Autophagic Process on Leishmania amazonensis by Synergistic Effect of Miltefosine and Innovative Semi-synthetic Thiosemicarbazone," Front. Microbiol, no. 8, p. 255, 2017.

[20] J. Kleeff, M. Kornmann, H. Sawhney, and M. Korc, "Actinomycin D induces apoptosis and inhibits growth of pancreatic cancer cells," International Journal of Cancer, vol. 89, no. 2, pp. 399-407, 2000.

[21] M. L. R. Lim, T. Minamikawa, and P. Nagley, “The protonophore CCCP induces mitochondrial permeability transition without cytochrome c release in human osteosarcoma cells," FEBS Letters, vol. 503, no. 1, pp. 69-74, 2001.

[22] F. P. Garcia, J. Henrique da Silva Rodrigues, Z. U. Din et al., "A3K2A3-induced apoptotic cell death of Leishmania amazonensis occurs through caspase- and ATP-dependent mitochondrial dysfunction," Apoptosis, vol. 22, no. 1, pp. 57-71, 2017.

[23] C. Paris, P. M. Loiseau, C. Bories, and J. Bréard, "Miltefosine induces apoptosis-like death in Leishmania donovani promastigotes," Antimicrobial Agents and Chemotherapy, vol. 48, no. 3, pp. 852-859, 2004.

[24] V. Jimenez, R. Paredes, M. A. Sosa, and N. Galanti, "Natural programmed cell death in T. cruzi epimastigotes maintained in axenic cultures," Journal of Cellular Biochemistry, vol. 105, no. 3 , pp. 688-698, 2008.

[25] D. Lazarin-Bidóia, V. C. Desoti, T. Ueda-Nakamura, B. P. Dias Filho, C. V. Nakamura, and S. O. Silva, "Further evidence of the trypanocidal action of eupomatenoid-5: Confirmation of involvement of reactive oxygen species and mitochondria owing to a reduction in trypanothione reductase activity," Free Radical Biology and Medicine, vol. 60, pp. 17-28, 2013.

[26] P. R. Murray, K. S. Rosenthal, G. S. Kobayashi, and M. A. Pfaller, Microbiologia Médica, Guanabara Koogan, Rio de Janeiro, 6th edition, 2000.

[27] B. P. da Silva, D. A. Cortez, T. Y. Violin et al., "Antileishmanial activity of a guaianolide from Tanacetum parthenium (L.) schultz bip," Parasitology International, vol. 59, no. 4, pp. 643646, 2010.

[28] A. D. Kinghorn, "Pharmacognosy in the 21st century," Journal of Pharmacy and Pharmacology, vol. 53, no. 2, pp. 135-148, 2001.

[29] G. Samuelsson, Drugs of Natural Origin: a Textbook of Pharmacognosy, Swedish Pharmaceutical Press, Stockholm, 5th edition, 2004.

[30] M. J. Balunas and A. D. Kinghorn, "Drug discovery from medicinal plants," Life Sciences, vol. 78, no. 5, pp. 431-441, 2005.

[31] E. Baumann, G. Stoya, A. Völkner, W. Richter, C. Lemke, and W. Linss, "Hemolysis of human erythrocytes with saponin affects the membrane structure," Acta Histochemica, vol. 102, no. 1, pp. 21-35, 2000.

[32] S. W. Perry, J. P. Norman, J. Barbieri, E. B. Brown, and H. A. Gelbard, "Mitochondrial membrane potential probes and the proton gradient: a practical usage guide," BioTechniques, vol. 50, no. 2, pp. 98-115, 2011.

[33] E. Brauchle, S. Thude, S. Y. Brucker, and K. Schenke-Layland, "Cell death stages in single apoptotic and necrotic cells monitored by Raman microspectroscopy," Scientific Reports, vol. 4, article no. 4698, 2014.

[34] A. J. Kowaltowski and A. E. Vercesi, "Mitochondrial damage induced by conditions of oxidative stress," Free Radical Biology and Medicine, no. 26, pp. 463-471, 1999.
[35] S. Elmore, "Apoptosis: a review of programmed cell death," Toxicologic Pathology, vol. 35, no. 4, pp. 495-516, 2007.

[36] A. K. Au, H. Bayir, P. M. Kochanek, and R. S. B. Clark, "Evaluation of autophagy using mouse models of brain injury," Biochimica et Biophysica Acta - Molecular Basis of Disease, vol. 1802, no. 10, pp. 918-923, 2010.

[37] M. C. Hewitt and P. H. Seeberger, "Solution and solid-support synthesis of a potential leishmaniasis carbohydrate vaccine," Journal of Organic Chemistry, vol. 66, no. 12, pp. 4233-4243, 2001.

[38] L. Menger, E. Vacchelli, S. Adjemian et al., "Cardiac glycosides exert anticancer effects by inducing immunogenic cell death," Science Translational Medicine, vol. 4, no. 143, Article ID 143ra99, 2012.

[39] F. Delmas, C. Di Giorgio, R. Elias et al., "Antileishmanial activity of three saponins isolated from ivy, $\alpha$ - hederin, $\beta$ hederin and hederacolchiside Al, as compared to their action on mammalian cells cultured in vitro," Planta Medica, vol. 66, no. 4, pp. 343-347, 2000. 


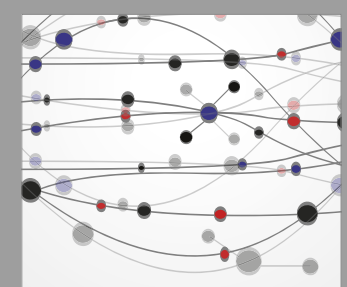

The Scientific World Journal
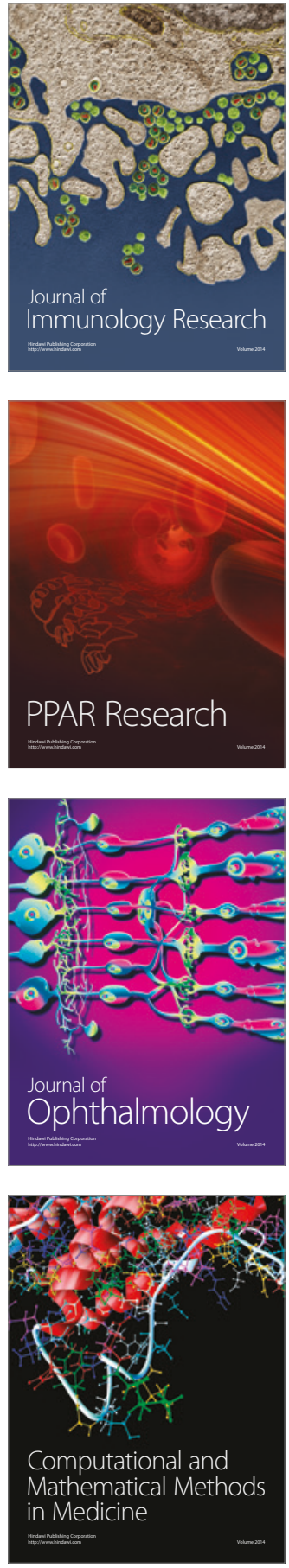

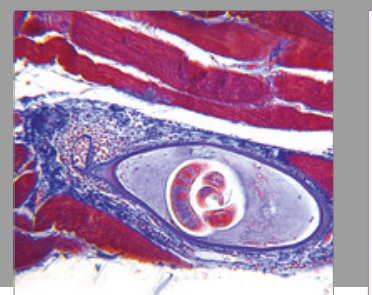

Gastroenterology Research and Practice
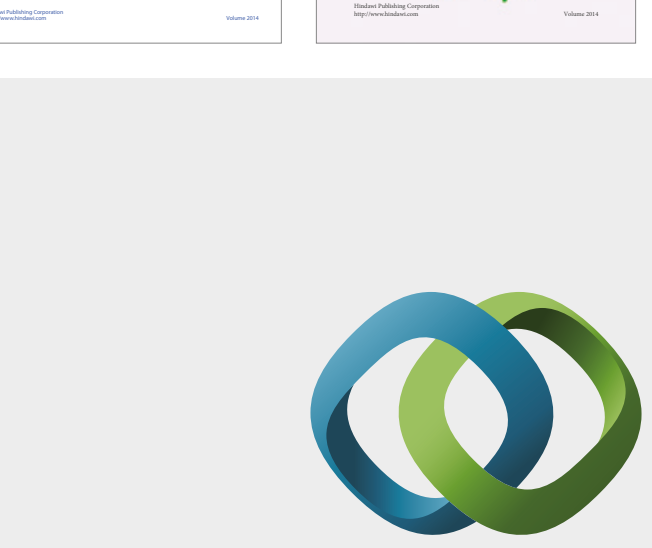

\section{Hindawi}

Submit your manuscripts at

https://www.hindawi.com
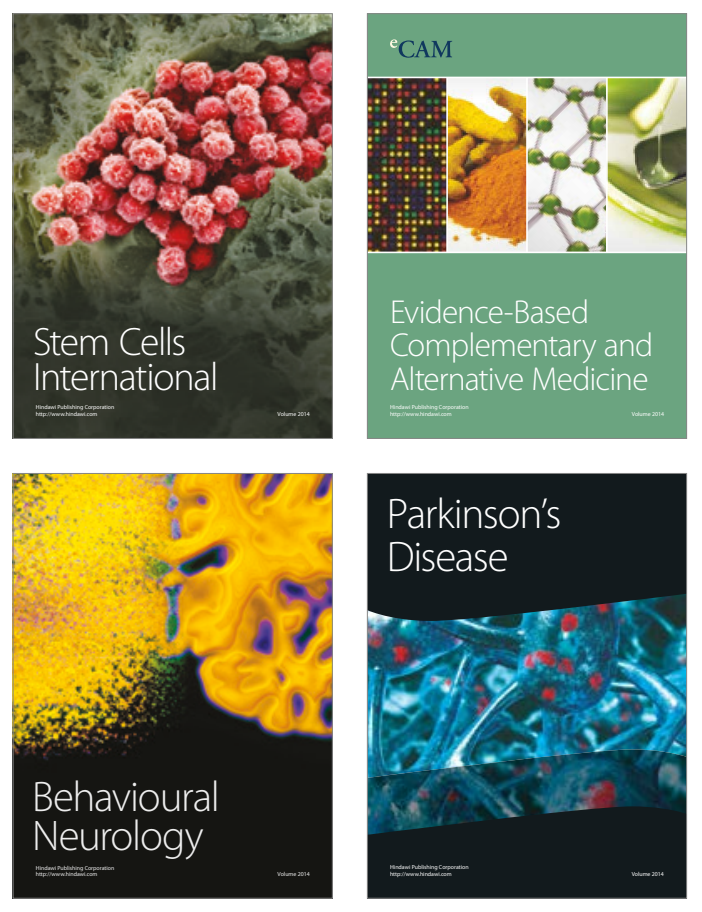
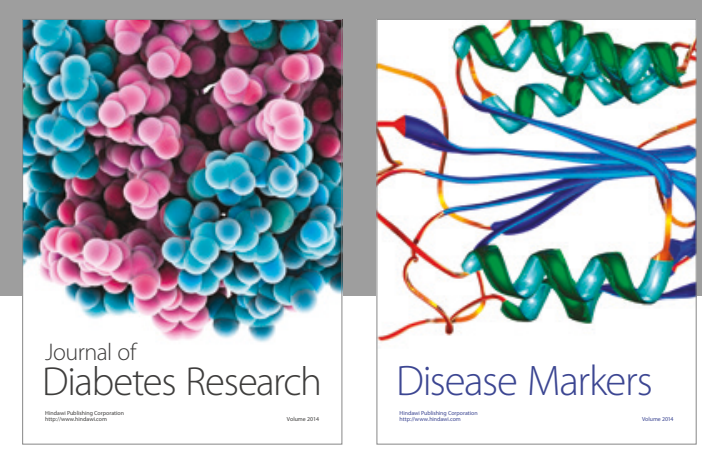

Disease Markers
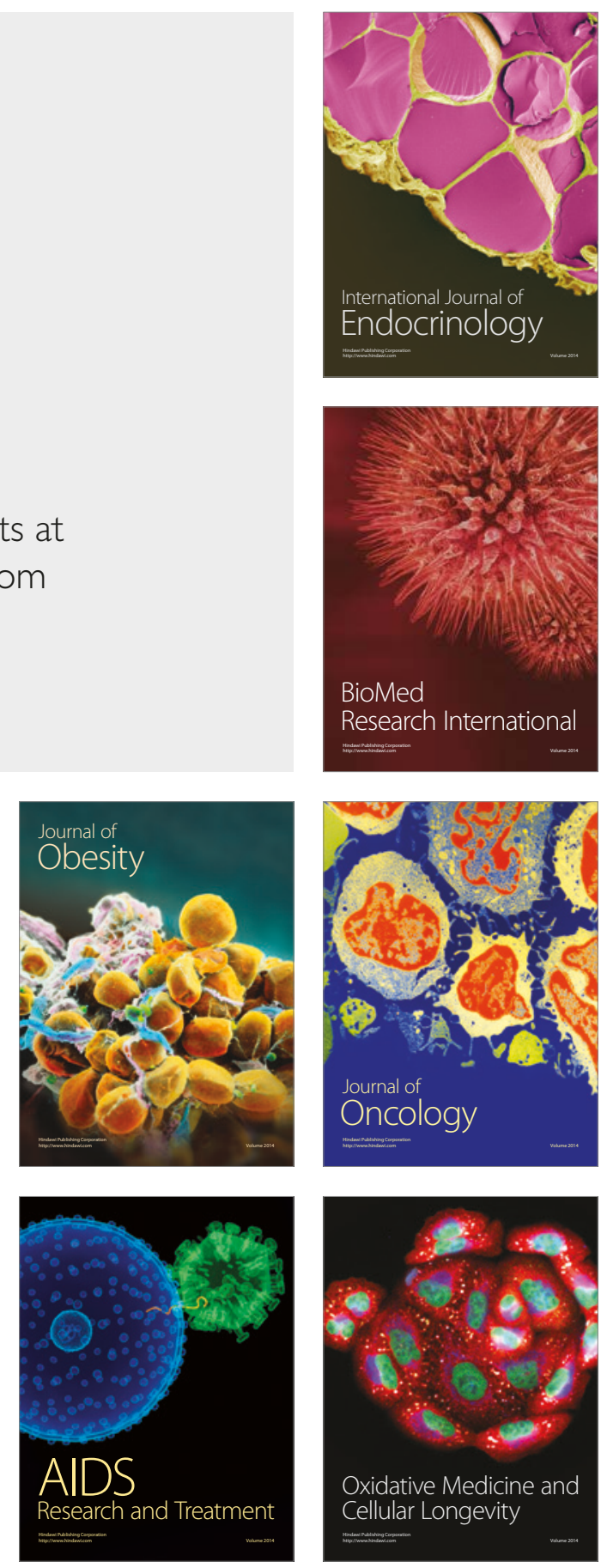